\title{
Exposure Assessment of Volatile Organic Compounds from Water in Taiwan Metropolitan and Petrochemical Areas
}

\author{
H. W. Kuo, ${ }^{1}$ T. F. Chiang, ${ }^{1}$ I. I. Lo, ${ }^{1}$ C. C. Chan, ${ }^{2}$ J. S. Lai, ${ }^{1}$ J. D. Wang ${ }^{2}$ \\ 'Institute of Environmental Health, China Medical College, Number 91, Huseh-Shin \\ RD, Taichung, Taiwan, Republic of China \\ ${ }^{2}$ Instltute of Occupational Medicine and Industrial Hygiene, College of Public Health, \\ National Taiwan University, Taiwan, Republic of China
}

\section{Received: 16 April 1997/Accepted: 22 August 1997}

The quality of drinking water is vital because it is consumed on a daily basis and thus has a major impact on our health. In Taiwan, the source of tap water is either river water or underground water. The quality of river and underground water is poor because it is contaminated by household and industrial waste water, seepage from landfills, and run-off from agricultural use. Due to the high content of organic compounds, water treatment plants often add chlorine to kill bacteria but the chlorine combines with the organic compounds to form disinfectant by-products (DBPs). As a result, tap water in Taiwan is unsuitable for consumption and should be boiled first. The term drinking water is used here as water that is directly consumed such as boiled water or bottled water. One reason why most of its rivers are contaminated is because of Taiwan's high density of large industrial companies, especially petrochemical companies (Taiwan EPA, 1995) Although petrochemical companies are very important to Taiwan's economy, they routinely discharge untreated waste water into rivers and underground water sources. This waste water has high levels of VOCs such as benzene, carbon tetrachloride, vinyl chloride, and some halogenated aromatics - all of which are known or suspected carcinogens (Gomez-Belinchon et al., 1991). In a previously published study (Pontius, 1990), long-term exposure to VOCs can harm the body's respiratory, hematopoietic, hepatic, or renal systems.

Compared to the U. S. which regulates 27 VOCs in drinking water, the only places in Taiwan which regulate VOCs are its two largest cities-- Taipei and Kaohsiung. However, the two city governments regulate only 12 VOCs. In other areas of Taiwan there are no regulations. Of the 12 VOCs, four are different kinds of total halomethane (THM). City government standards prohibit THM concentrations from exceeding $0.15 \mathrm{mg} / \mathrm{L}$ (Taiwan Water Supply Corp., 1995). These concentrations are closely related to the amount of chlorine added in the water treatment plants or concentrations of organic compounds in the water source. Previous studies (Kuo et al., 1996; Bradaway, 1992), including ones done by the authors, have found significant concentrations of THMs and lesser concentrations of other VOCs in water treatment plants. Other sources of VOCs in tap water include water distribution pipes with an inner vinyl lining made of certain asbestos cement (Larsen et al., 1983) and water storage tanks at households that are not regularly cleaned. These organic compounds may produce VOCs when combined with free forms of chlorine. 
Morris, et al (1992) used meta-analysis to find a positive association between consumption of chlorination by-products in drinking water and bladder and rectal cancer in humans. In recent years, cancer has become one of the top ten leading causes of death in Taiwan and the incidence rate of rectal and bladder cancer has been rising(Taiwan DOH, 1996). Except for lifestyle changes, reasons for the rising incidence of cancer among Taiwanese may be related to chlorination by-products in the drinking water. The first step in drawing a clear link between water quality and the incidence of cancer is to investigate the exposure assessment of VOCs from household water. The authors hope this study can assist the Taiwan government in its efforts to improve the overall quality of water.

\section{MATERIALS AND METHODS}

Sampling was done in the three metropolitan areas. In Taipei samples were taken from the ten districts, in Taichung from the eight districts and from the ten districts in Taiwan's petrochemical center, Kaohsiung. In each district, five samples were taken from households and one from a nearby gas station. A total of one-hundred and forty samples were taken.

Twenty-four purgable VOCs were obtained from Supelco Inc. (Supelcol, Bellefonte, Pa., USA). Internal standards of Bromochloromethane, 1,4diflurobenezene and chlorobenzene-d5 were purchased from Supelco Inc. 1,2dichloroethane-d4, toluene-d8 and p-bromofluorobenzene were used as surrogate standards.

VOCs concentrations were determined using modified U.S. EPA methods 524.2 (Kuo et al., 1996). A $25 \mathrm{~mL}$ water sample was collected after tap water ran for 5 minutes. A $5 \mathrm{~mL}$ water sample was injected into a "purge and trap" device (Tekma

Table 1. VOC Concentrations $(\mu \mathrm{g} / \mathrm{L})$ of tap water in three metropolitan areas

\begin{tabular}{lccc}
\hline & Taipei & Taichung & Kaohsiung \\
\hline THMs $\quad$ Chloroform & $77.47 \pm 31.69$ & $26.91 \pm 10.20$ & $104.67 \pm 69.41$ \\
$\quad$ Bromodichloromethane & $54.32 \pm 38.26$ & $17.36 \pm 9.64$ & $58.26 \pm 44.14$ \\
$\quad$ Dibromochloromethane & $23.15 \pm 15.10$ & $9.55 \pm 6.98$ & $30.27 \pm 32.61$ \\
Toluene & ND & ND & $16.14 \pm 26.78$ \\
1,2-dichloroethane & $4.09 \pm 13.91$ & $8.00 \pm 22.07$ & $19.46 \pm 11.18$ \\
Ethylbenzene & $3.88 \pm 6.63$ & $6.56 \pm 5.04$ & $4.31 \pm 2.85$ \\
Trichloroethene & $2.27 \pm 5.42$ & ND & $0.43 \pm 2.11$ \\
1,1,1-trichloroethane & ND & $4.97 \pm 7.01$ & ND \\
Tetrachloromethane & ND & $0.59 \pm 1.47$ & $0.03 \pm 0.19$ \\
Benzene & ND & ND & ND \\
Trans-1,3-dichloropropene & $0.29 \pm 0.99$ & ND & ND \\
Cis-1,3-dichloropropene & ND & ND & $0.22 \pm 1.53$ \\
\hline
\end{tabular}


LSC 3000, Cincinnati, Ohio, USA) with a trap of Tenax/Silica gel/Charcoal. A cryofocus was used to concentrate the VOC concentrations. The purge time was at least 11 minutes with purge flow rate of $40 \mathrm{ml} /$ minute Purgable VOCs were collected in a trap column and were thermally desorbed at $180{ }^{\circ} \mathrm{C}$ for 5 minutes. VOCs were then passed into cryogenically focused device at $-120{ }^{\circ} \mathrm{C}$ with liquid nitrogen before injection. VOC analysis was performed by a high resolution gas chromatographic/mass spectrometry(GC/MS) technique(Perkin Elmer Q-Mass 910, Norwalk, CT, USA). Ionization mode was $70 \mathrm{eV}$ with a mass scan range of 10-650 amu. The capillary column used was DB5 $(30 \mathrm{~m} / 0.25 \mathrm{~mm} / 0.25 \mu \mathrm{m})$. The initial oven temperature of $\mathrm{GC}$ was set at $35^{\circ} \mathrm{C}$ for 3 minutes and incrementally increased at a rate of $4^{\circ} \mathrm{C} /$ minute until it reached $100^{\circ} \mathrm{C}$.

Five field duplicates were used during testing to ensure consistent results. Results showed a relative standard deviation (RSD) for VOCs of less than 10\%. A batch of samples from a district were tested using a laboratory blank reagent, field blank reagent, and a laboratory fortified blank. The detection limit of VOCs ranged from 0.02 to $1.48 \mu \mathrm{g} / \mathrm{L}$.

\section{RESULTS AND DISCUSSION}

VOC concentrations in the three metropolitan areas showed significant differences. See Table 1. Except for THM concentrations, all other VOC concentrations were relatively low. THM concentrations were highest in Kaohsiung and lowest in Taichung. Of all VOCs tested, chloroform concentrations were highest and bromoform was not detected. In all three areas, Toluene and 1,2-Dichloroethane were detected. Ethylbenzene, 1, 1, 1-Trichloroethane, Benzene, and trans- 1,3Dichloropropane were not consistently found in the three areas due to differences in water sources and storage equipment. In a comparison with several countries around the world, Taiwan ranks number one with the highest concentration of THM. In 1996 Hassan found THM concentrations in Egypt ranged from 18.3 to $67.3 \mu \mathrm{g} / \mathrm{L}$. Japan's THM concentrations ranged from 12.5 to $37.5 \mu \mathrm{g} / \mathrm{L}$ and Sweden's was 0.2 to $25.0 \mu \mathrm{g} / \mathrm{L}$. The main reason for Taiwan's high concentration of THM is the water sources are contaminated by industrial, agricultural, and household waste water. This results in water sources having concentrations of precursors. In a 1995 study by Chiang, water quality in Kaohsiung was so poor that water treatment plants added extra chlorine to the water supply. Concentrations were so high, chlorine was added that it could be smelled, especially during summer. An additional reason may be because household storage tanks in Taiwan generally are not cleaned on a regular basis which increases the likelihood of organic precursors. Fortunately, except for THM, other chemical concentrations were found to be relatively low. This suggests that at present the nearby petrochemical plants have not polluted the water source. This study provides valuable baseline data that can be used by the government or water treatment plants for monitoring the quality of household water. 


\begin{tabular}{lccc}
\hline & Taipei & Taichung & Kaohsiung \\
\hline THMs & $15.52 \pm 27.35$ & $4.24 \pm 4.16$ & $13.26 \pm 38.42$ \\
$\quad$ Chloroform & $13.39 \pm 26.13$ & $4.24 \pm 4.16$ & $5.95 \pm 15.87$ \\
$\quad$ Bromodichloromethane & $2.13 \pm 5.46$ & ND & $6.51 \pm 30.37$ \\
Dibromochloromethane & ND & ND & $0.80 \pm 3.68$ \\
Toluene & $12.07 \pm 30.71$ & $6.40 \pm 13.79$ & $14.40 \pm 19.47$ \\
1,2-dichloroethane & $2.33 \pm 4.04$ & $5.70 \pm 4.34$ & $26.21 \pm 16.63$ \\
Ethylbenzene & $0.75 \pm 2.81$ & $0.59 \pm 2.50$ & $0.25 \pm 1.64$ \\
Trichloroethene & ND & ND & ND \\
1,1,1-trichloroethane & ND & ND & ND \\
Tetrachloromethane & ND & ND & ND \\
Benzene & ND & ND & $0.08 \pm 0.51$ \\
Trans-1,3-dichloropropene & ND & ND & ND \\
Cis-1,3-dichloropropene & ND & ND & $0.10 \pm 0.63$ \\
\hline
\end{tabular}

VOC concentrations found in drinking water were significantly lower than concentrations in tap water. See Table 2. THM concentrations were highest among all VOCs. Toluene, 1,2-Dichloroethane, and Ethylbenzene were detected in all three areas. Benzene and cis-1,3-Dichloropropane were found in Kaohsiung. THM concentrations in drinking water were actually lower in Kaohsiung compared to Taipei because only $20 \%$ of people surveyed in Kaohsiung used tap water as their primary source of drinking water. Most people consumed mineral water or mountain water. These results can be used in mathematical models to perform risk assessment in the three metropolitan areas.

Of the four sources of drinking water, VOC concentrations were highest in tap water and lowest in mountain water. See Table 3. Significantly, VOCs were detected even in mineral water bottled in Taiwan. The source of this mineral water is most likely inadequate purification methods at the bottling plants or even tap water. Results that underground water showed lower VOC concentrations than tap water, show the former is not being contaminated by waste water from nearby factories. However samples from underground water were taken from relatively shallow wells dug by residents for personal use and not from wells used by the government to monitor the quality of underground water. So this study's results concerning VOC concentrations in underground water cannot represent the true situation. Because of Taiwan's recent trend of consuming mineral water, the government started periodically monitoring for biological organisms but not 


\begin{tabular}{lcccc}
\hline & tap water & $\begin{array}{c}\text { underground } \\
\text { water }\end{array}$ & $\begin{array}{c}\text { mountain } \\
\text { water }\end{array}$ & mineral water \\
\hline THMs & $21.35 \pm 42.04$ & $1.26 \pm 1.78$ & $0.43 \pm 1.16$ & $7.21 \pm 16.87$ \\
$\quad$ Chloroform & $12.40 \pm 21.60$ & $1.26 \pm 1.78$ & $0.43 \pm 1.16$ & $5.77 \pm 12.68$ \\
$\quad$ Bromodichloromethane & $8.02 \pm 32.69$ & ND & ND & $1.44 \pm 4.32$ \\
Dibromochloromethane & $0.93 \pm 3.95$ & ND & ND & ND \\
Toluene & $12.08 \pm 22.45$ & $24.52 \pm 27.28$ & $15.72 \pm 17.90$ & ND \\
1,2-dichloroethane & $18.10 \pm 81.53$ & $7.36 \pm 1.66$ & $3.13 \pm 3.15$ & $59.02 \pm 67.75$ \\
Ethylbenzene & $0.57 \pm 2.42$ & ND & $0.72 \pm 2.77$ & ND \\
Trichloroethene & ND & ND & ND & ND \\
1,1,1-trichloroethane & ND & ND & ND & ND \\
Tetrachloromethane & ND & ND & ND & ND \\
Benzene & $0.09 \pm 0.55$ & ND & ND & ND \\
Trans-1,3-dichloropropene & ND & ND & ND & ND \\
Cis-1,3-dichloropropene & ND & ND & $0.28 \pm 1.07$ & ND \\
\hline
\end{tabular}

organic compounds. So results from this study can be used as a reference for better understanding of the quality of mineral water bottled in Taiwan. McNeal et al. (1995) surveyed THM and other chemical contaminants in processed food such as soft drinks, juices, beer, and waters from processed vegetables. They found chloroform in ranges from none to $94 \mathrm{ng} / \mathrm{g}$ and benzene and toluene residues were found in two and three foods respectively. This compound was found to be related to the water source. Although this data is not available in Taiwan, food and beverages processed here using tap water may contain high concentrations of THM. This possibility needs to be further studied in order to determine VOC concentrations.

Table 4 compares VOC concentrations from tap water and drinking water. Results showed following boiling, THM concentrations decreased by about $80 \%$. Compounds with low boiling points such as trichloroethylene, 1-1 trichloroethane and tetrachloromethane were vaporized and not detected following boiling. Although some THMs and DBPs such as haloacetic acids, haloacetonitrites, haloketones, and chloropicrin, etc. were detected after boiling, this suggests that this is an important step before consumption. Also water treatment methods (including coagulation, settling and filtration) need to be improved to effectively remove all DBPs. In order to make the tap water safe for direct consumption, granular activated carbon (GAC) should be used to adsorb organic compounds. Also ozone, not chlorine, should be added to the water supply because it does not produce DBPs.

Acknowledgments. This study was supported by special grant from the National Science Council NSC85-2621-P039-002 
Table 4. Comparison of VOCs in tap water and drinking water after boiling

\begin{tabular}{lccc}
\hline & tap water & drinking water & P value \\
\hline THMs & $80.05 \pm 62.14$ & $16.45 \pm 37.90$ & $<0.001$ \\
$\quad$ Chloroform & $44.51 \pm 33.01$ & $9.56 \pm 19.62$ & $<0.001$ \\
$\quad$ Bromodichloromethane & $24.81 \pm 32.16$ & $6.18 \pm 28.81$ & 0.005 \\
$\quad$ Dibromochloromethane & $10.73 \pm 27.00$ & $0.72 \pm 3.48$ & 0.023 \\
Toluene & $14.34 \pm 20.09$ & $14.34 \pm 22.05$ & 0.552 \\
1,2-dichloroethane & $5.13 \pm 4.64$ & $13.95 \pm 71.76$ & 0.383 \\
Ethylbenzene & $0.76 \pm 3.09$ & $0.44 \pm 2.13$ & 0.275 \\
Trichloroethene & $1.79 \pm 4.78$ & $\mathrm{ND}$ & - \\
1,1,1-trichloroethane & $0.24 \pm 0.92$ & $\mathrm{ND}$ & - \\
Tetrachloromethane & $\mathrm{ND}$ & $\mathrm{ND}$ & - \\
Benzene & $0.07 \pm 0.49$ & $0.07 \pm 0.48$ & 0.986 \\
Trans-1.3-dichloropropene & $0.21 \pm 1.51$ & $\mathrm{ND}$ & - \\
Cis-1,3-dichloropropene & $\mathrm{ND}$ & $\mathrm{ND}$ & - \\
\hline
\end{tabular}

\section{REFERENCES}

Beavers JD, Himmelstein JS, Hammond SK, Smith TJ, Kenyon EM, Sweet CP (1996). Exposure in a household using gasoline-contaminated wate. J Occup Environ Med 38:35-8

Bradaway MI (1992) Trihalomethane in drinking water supplies and reused water. Bull Environ Contam Toxicol 48:157-67

Chiang TC (1995) By-products of drinking water and treatment techniques in Taiwan. EPA-84-E3JI-09-01, Taiwan EPA.

El-Dib MA and Ali RK ( 1992) Trihalomethanes in chlorinated drinking water of Cairo, Egypt. Bull Environ Contam Toxicol 48:378-86

El-Dib MA and Ali RK (1992) Trihalomethanes and halogenated organic formation in water treatment plant. Bull Environ Contam Toxicol 49:381-7

Gomez-Belinchon JI, Grimalt JO and Albaiges J (1991) Volatile organic compounds in two polluted rivers in Barcelona (Catalonia, Spain) Water Res 25:577-89

Kuo HW, Lo II, Chan CC, Lai JS, Wang JD (1996) Volatile organic compounds in drinking water near petrochemical factories in Taiwan. Chemosphere 33:913-20

Larsen CD, Love TO, Reynolds G ( 1983) Tetrachloroethylene leached from lined asbestos-cement pipe into drinking water. J Am Water Work Assoc 75:1848.

McNeal MP, Hollifield HC, Diachenko GW (1995) Survey of trihalomethanes and other volatile chemical contaminants in processed foods by purge-and trap capillary gas chromatography with mass selective detection. JAOAC 78:391-7 
Morris RD, Audet AM, Angelillo IF, Chalmers TC and Mosteller F (1992)

Chlorination, chlorination by-products and cancer: a meta-analysis. Am J Public Health 22:955-63

Pontius FW (1990) Toxicology and drinking water regulation. J Am Water Works Assoc 82:14-17

Pontius FW ( 1995) An update of the Federal drinking water regs. J Am Water Works Assoc 87:45-8.

Taiwan Water Supply Corp (1995). The Statistical Data and Water Quality. Taichung, Taiwan, R.O.C.

Taiwan Department of Health ( 1996) Cancer Registry Annual Report. Taipei, Taiwan, R.O.C., 12-15

Taiwan EPA (1995) Annual Report of Environmental Protection in Taiwan. Taipei, Taiwan, R.O.C 